\title{
The origins and spread of stock-keeping: the role of cultural and environmental influences on early Neolithic animal exploitation in Europe
}

\author{
Katie Manning ${ }^{1}$, Sean S. Downey ${ }^{1}$, Sue Colledge ${ }^{1}$, James Conolly ${ }^{2}$, \\ Barbara Stopp ${ }^{3}$, Keith Dobney ${ }^{4} \&$ Stephen Shennan $^{1}$
}

It has long been recognised that the proportions of Neolithic domestic animal species—cattle, pig and sheep/goat-vary from region to region, but it has hitherto been unclear how much this variability is related to cultural practices or to environmental constraints. This study uses hundreds of faunal assemblages from across Neolithic Europe to reveal the distribution of animal use between north and south, east and west. The remarkable results present us with a geography of Neolithic animal society - from the rabbit-loving Mediterranean to the beef-eaters of the north and west. They also demonstrate that the choices made by early Neolithic herders were largely determined by their environments. Cultural links appear to have played only a minor role in the species composition of early Neolithic animal societies.

Keywords: Europe, Neolithic, zooarchaeology, herding strategies, food production systems

\section{Introduction}

The founder species of Neolithic European herding strategies—cattle, sheep, goat and pig - were first domesticated in south-west Asia c. $8500 \mathrm{BC}$. Alongside domestic crops such as wheat, barley and pulses (Colledge et al. 2005), they dispersed westwards throughout Europe, reaching the limits of north-west Europe by $c .4000 \mathrm{BC}$. This spread of early agropastoral lifeways correlates with fundamental changes in past human demography, ecology and social organisation (Bocquet-Appel \& Bar-Yosef 2008; Collard et al. 2010; Schibler $\&$ Jacomet 2010). Recent studies have, furthermore, brought to light a high degree of variability in early European agricultural systems, demonstrating both the historical and ecological contingency of food production systems (e.g. Döhle 1997; Arbogast et al. 2001; Bonsall et al. 2002; Tresset \& Vigne 2007; Schibler \& Jacomet 2010). However, the role of ecological and cultural influences on early Neolithic herding strategies remains ill-defined. Both have been considered as potential contributors to the observed variation, but there has been little attempt to disentangle the relative effects of ecological $v$ s cultural factors.

\footnotetext{
Institute of Archaeology, University College London, 31-34 Gordon Square, London WC1H OPY, UK

Department of Anthropology, Trent University, Peterborough, ON, K9J 7B8, Canada

Institut für Prähistorische und Naturwissenschaftliche Archäologie (IPNA), Spalenring 145, CH-4055 Basel,

Switzerland

4 Department of Archaeology, University of Aberdeen, St Mary's, Elphinstone Road, Aberdeen AB24 3UF, UK 
Reanalyses of the vast body of published zooarchaeological data from Europe (Manning et al. 2013), have revealed a correspondence in the relative proportions of domestic taxa between south-east Europe and central Europe, which diverges from the zooarchaeological record of the Mediterranean coast. Our new study further explores these data, in order to characterise regional variability in early Neolithic animal bone assemblages across Europe. While many of the patterns we identify confirm earlier conclusions, particularly in regard to the regionalisation of herding strategies, our dataset enabled us to distinguish the relative importance of ecological, spatial and cultural factors and to conclude that when dealing with broad-scale patterns in animal exploitation, environmental factors are more important than cultural ones.

\section{Method and dataset}

Published zooarchaeological data from Europe have been collected in a comprehensive database at University College London, deriving from an AHRC-funded project entitled the Origins and Spread of Stock-keeping (OSSK). Wild and domestic mammals, birds, fish, molluscs and crustaceans are included. Taxa were entered at the level of identification published by the original analysts, whether to species or genera, at the more general level of family (or 'type'), or according to body size (e.g. large/small mammal). Where provided, the NISP (Number of Identified Specimens) for each taxon was recorded. Where possible, age and sex trends, biometric information, pathological signatures, body part distribution and isotopic or DNA data were also recorded, together with the site phase, cultural affiliation and geographic location.

The dataset for this study consists of published NISP data of vertebrate taxa from 235 European archaeological sites (Figure 1), comprising 250 culturally distinct phases, covering the early and middle Neolithic. The middle Neolithic site phases that are included are those assigned to the Cerny, Chassey, Michelsberg and Trichterbecherkultur (TRB) cultural complexes. Although these cultures are characterised as middle Neolithic in regional sequences, they are earlier than, or contemporary with, early Neolithic developments in Britain and Scandinavia and therefore relevant to the spread of herding strategies to these latter regions.

For the purpose of the analyses below, sites were grouped into broad geographic regions: south-east Europe (Greece, Macedonia, Moldova, Serbia, Bulgaria, Romania and Croatia), the central and south-west Mediterranean (south-eastern France, Spain, Italy and Portugal), central Europe (Germany, Hungary, Poland, Slovakia, central and north-eastern France, Switzerland, Austria and Czech Republic), and north and north-west Europe (northern France, England, Ireland, Wales, Scotland, Belgium, Netherlands, Denmark, Finland and Sweden).

Our foremost interest is in the primary meat-bearing taxa. These include domestic cattle (Bos taurus), sheep/goat (Ovis aries/Capra hircus) and pig (Sus scrofa domesticus), as well as red deer (Cervus elaphus), roe deer (Capreolus capreolus), wild boar (Sus scrofa ferus) and aurochs (Bos primigenius). These taxa tend to make up the overwhelming majority of Neolithic animal bone assemblages, and (in varying proportions) constitute the staple of early Neolithic herding and hunting strategies. To identify continental-scale patterns we

(C) Antiquity Publications Ltd. 


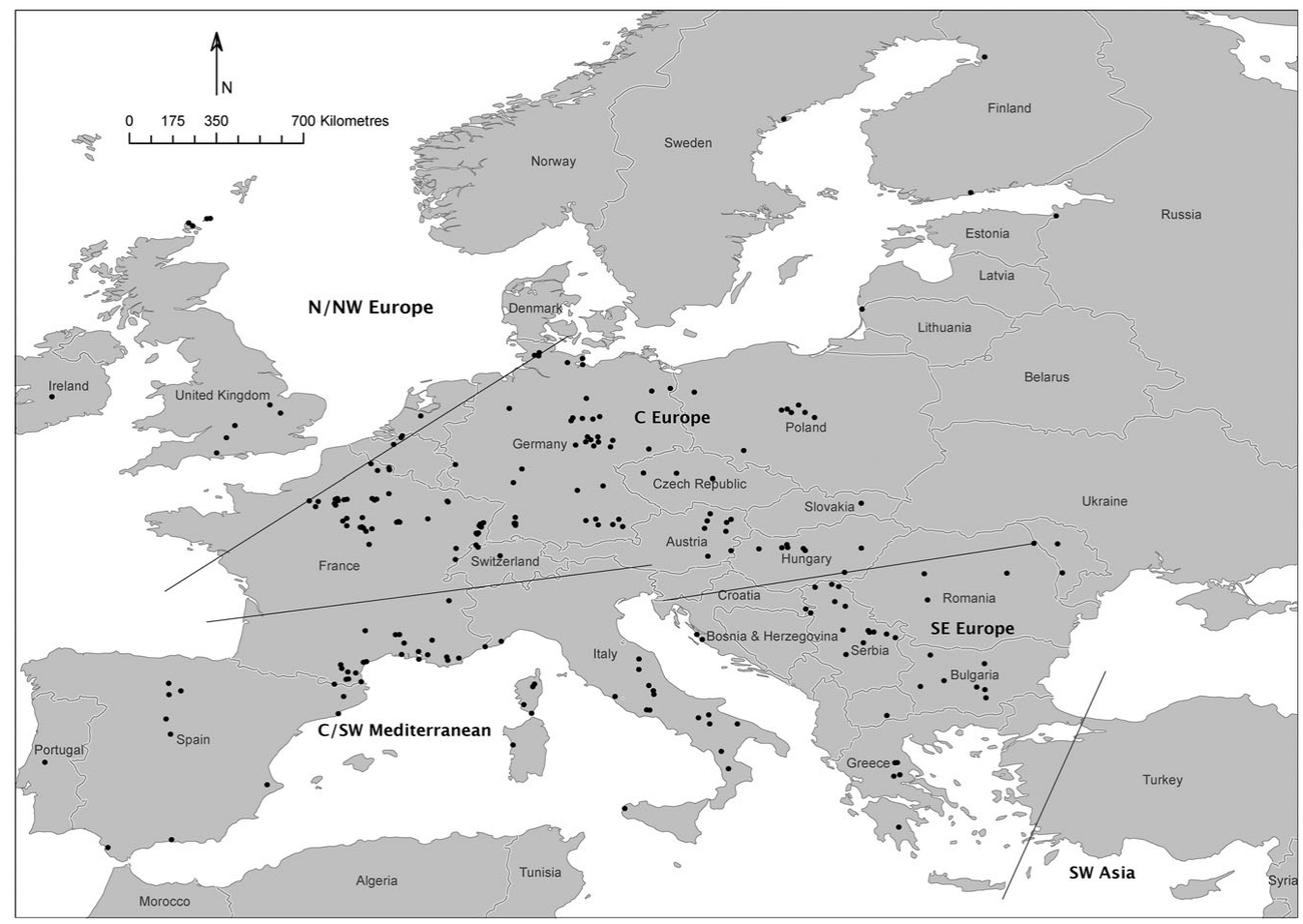

Figure 1. Map of study area showing site distribution and regional boundaries (sites from south-west Asia are not shown on the map).

undertook a series of Correspondence Analyses (CA) on a dataset comprising the NISP for the relevant site phases. This method of analysis has proved useful in the investigation of broad scale spatio-temporal changes in taxonomic composition (Colledge et al. 2005; Tresset \& Vigne 2007; Conolly et al. 2011; Manning et al. 2013; Rowley-Conwy et al. 2013).

The results of the CA reveal clear regional patterns, and from this basis we also investigated intra-regional variations in animal exploitation. For these analyses, we expanded our taxa list to include a greater number of wild species. In particular we focused on variation in the frequency distribution of different taxa in the central and south-west Mediterranean, as well as between central Europe (particularly Linearbandkeramik (LBK) sites) and north and north-west Europe.

Next, we used multi-linear regression, analysis of variance (ANOVA), and analysis of covariance (ANCOVA) to determine the relative explanatory power of environmental and cultural factors in accounting for variation in the frequency of different species. A reduced dataset was used for this analysis in order to mitigate the effects of small sample size arising from the fact that some cultural categories had only one or two associated phases. Hence, a minimum number of seven site phases per cultural category was set for inclusion in the analysis, resulting in a dataset comprising 227 site phases. The cultures represented, and the number of sites affiliated to them, are shown in Table 1. Following similar methods to Conolly et al. (2012), we first tested for ecological influence by conducting (C) Antiquity Publications Ltd. 
Table 1. List of cultural categories and number of associated site phases used in the ANCOVA.

\begin{tabular}{lc}
\hline & Site phases \\
\hline British early Neolithic & 7 \\
Cardial & 32 \\
Chassey & 10 \\
Early Linearbandkeramik & 7 \\
Greek early Neolithic & 7 \\
Impressa & 22 \\
Karanovo & 7 \\
Linearbandkeramik & 53 \\
Micheslberg & 7 \\
Rubané & 31 \\
Starcevo-Koros-Cris & 23 \\
Trichterbecher & 8 \\
Villeneuve Saint-Germain & 13 \\
Total & $\mathbf{2 2 7}$ \\
\hline
\end{tabular}

a multi-linear regression using 11 continuous bioclimatic variables from the WorldClim gridded data source (Hijmans et al. 2005) and three additional derived geographic variables, shown in Table 2. Local ecological factors were extracted for each site that has a published zooarchaeological assemblage based on its geographic coordinates using ArcMap 9.3 (ESRI 2009). Most of the independent variables were normally distributed, and only prdry and slope required log transformation before analysis. Frequency values for the animal NISP response variables were arcsine transformed, a common method for positively skewed frequency data (Legendre \& Legendre 1998; Crawley 2005: 247-48), and 'no data' was treated as a 'zero' NISP count.

An ANCOVA was used to combine the continuous environmental variables with cultural factors in an additive model that determines how much combined variance in the distribution of NISP counts can be explained. The residuals from the multi-linear regression of environment alone were then used to calculate partial correlations and to conduct a twoway analysis of variance (ANOVA) on culture that assessed relative explanatory power after the effects of environment have been taken out. Linear models such as these are commonly used statistical methods, and are useful for providing estimates of the relationship between species abundance records and environmental covariates. All statistical analyses were conducted with the R statistical computing language (R Development Core Team 2011).

\section{Results}

Regional patterns in animal exploitation strategies

Correspondence Analysis was carried out on a dataset that included all early and middle Neolithic site phases, each domestic taxon and a combined 'wild' category, comprising the four wild taxa (roe deer, red deer, wild boar and aurochs). Seventeen site phases were identified as outliers and were therefore omitted from the analysis. The high number of

(C) Antiquity Publications Ltd. 
Table 2. Environmental variables and their means of calculation.

\begin{tabular}{|c|c|c|}
\hline Code & Name & Description \\
\hline tpavg & Annual mean temperature & In ${ }^{\circ}$ Celsius \\
\hline tpmrd & Mean diurnal range & Mean of monthly (tpmax-tpmin) \\
\hline tpiso & Isothermality & (tpmrd / tprng)* 100 \\
\hline tpcov & Temperature seasonality & (standard deviation of monthly tpavg)*100 \\
\hline tpmax & Max. temperature of warmest month & \\
\hline tpmin & Min. temperature of coldest month & \\
\hline tprng & Temperature annual range & tpmax-tpmin \\
\hline prtot & Annual precipitation & In millimetres \\
\hline prwet & Precipitation of the wettest month & \\
\hline prdry & Precipitation of the driest month & \\
\hline prcov & Precipitation seasonality & Coefficient of variation \\
\hline waterdist & Distance from water & $\begin{array}{l}\text { Euclidean distance in metres from rivers } \\
\text { calculated from CCM river and catchment } \\
\text { database, version } 2.1 \text { (de Jager \& Vogt 2010) }\end{array}$ \\
\hline roughness & Terrain roughness & $\begin{array}{l}\text { Standard deviation / mean of the elevation in } \\
\text { metres within a } 100 \mathrm{~km} \text { radius }\end{array}$ \\
\hline slope & Terrain slope & $\begin{array}{l}\text { Measured in angular degrees, } \mathrm{z} \text { factor }= \\
0.00001395\end{array}$ \\
\hline
\end{tabular}

assemblages with very small NISP counts exerted too strong an influence on axis 2, and therefore a minimum NISP of 100 per site phase was set for inclusion in all analyses.

The resultant bi-plot (Figure 2), comprising 233 phases (221 sites) and four vertebrate groups, reveals a strong dichotomy on both axes. Axis 1 distinguishes between wild and domestic taxa (accounting for 51.9 per cent of inertia in the dataset) whilst axis 2 distinguishes between the domestic taxa, with cattle and pig having positive values on axis 2 (accounting for 29.4 per cent inertia in the dataset), and sheep/goat having negative values. These patterns in taxonomic distribution also correlate with geographical region. The majority of central European and north and north-west European site phases, which are strongly associated, have positive values on both axes, indicating a greater association with cattle and pig remains. In contrast, the central and south-west Mediterranean site phases have negative values on axis 2, indicating a greater representation of sheep/goat remains and, to a lesser degree, wild taxa. South-east Europe and the Balkans (which comprises both the Mediterranean, i.e. Greek and Dalmatian coast, and the Balkan, i.e. Starcevo-Koros-Cris, site phases), appear to be pivotal between the central and south-west Mediterranean and central and north and north-west European sites.

There are, however, some exceptions. A number of central and north-west European sites, with negative values on axis 1 , show a greater association with cattle. For north and northwest Europe, five of the eight sites are from Orkney. This seeming preference for sheep/goat in Orkney, when compared to the cattle-dominated assemblages from southern Britain, is well known (McCormick 1984; Harman 2009; Schulting 2013), and may be due to the greater availability of coastal grasslands and the resilience of these animals. The outliers from central Europe are less easily explained, including three German and one Hungarian site belonging to the LBK and Starcevo-Koros-Cris cultures.

(C) Antiquity Publications Ltd. 


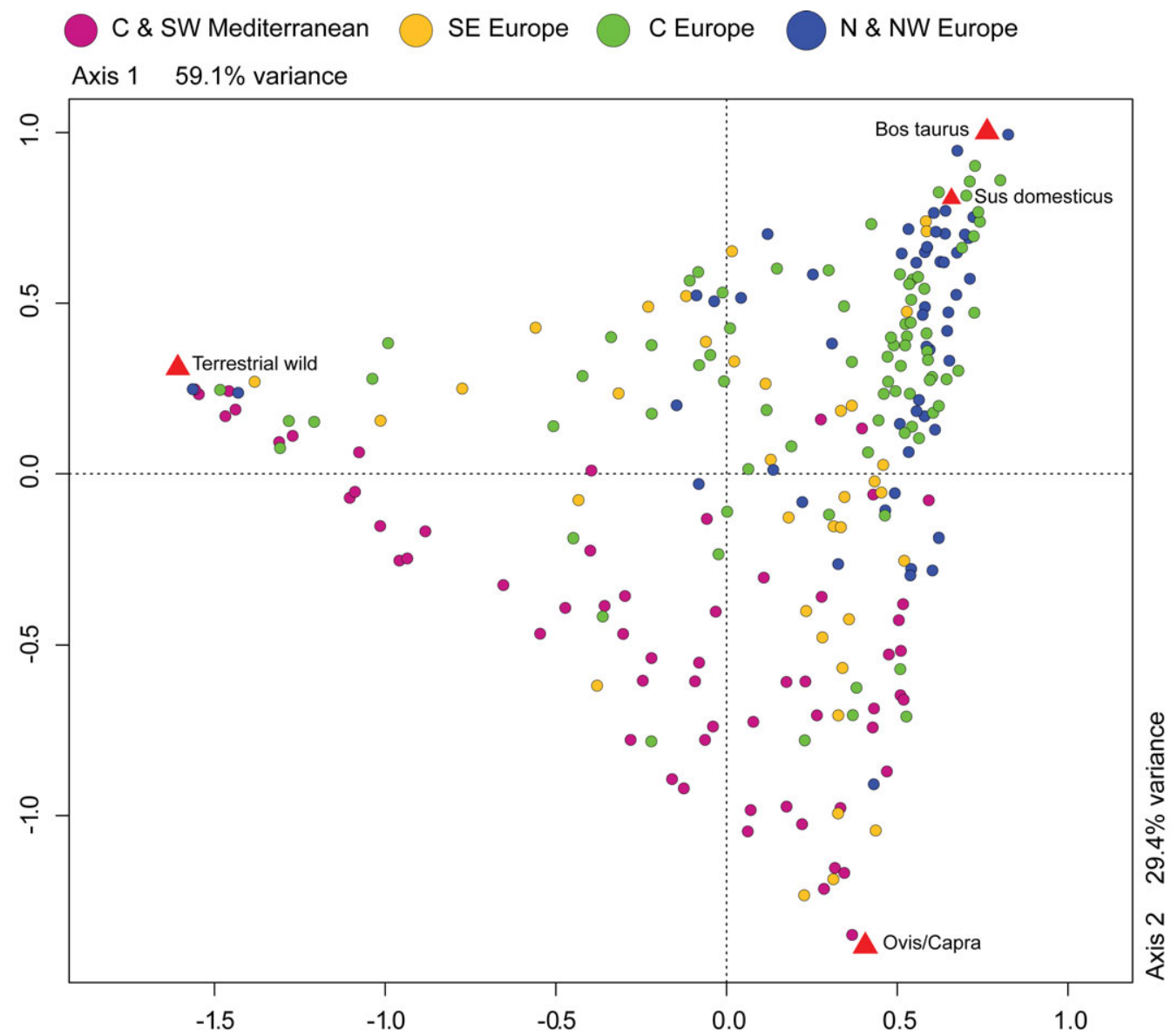

Figure 2. Correspondence analysis plot of animal bone assemblage NISP values from all early Neolithic site phases, categorised by region. Species contributions are weighted according to column mass.

The sites with negative values on axis 1 are those with a greater representation of wild taxa. For central Europe these belong primarily to the earliest phases of the Neolithic. In Switzerland, for example, this includes the La Hoguette site of Le Locle-Col des Roches, whilst in southern Germany four of the outlying sites belong to the earliest LBK. The persistence of high numbers of wild taxa during the early Neolithic in southern Germany has already been noted (Döhle 1993; Manning et al. 2013). Whilst local ecology is likely to have played a role in these regional patterns (Döhle 1993), our recent analysis indicates a strong temporal trend in central Europe, with higher frequencies of terrestrial wild animals being present in the earliest and early LBK phases (Manning et al. 2013). For north and north-west Europe the three sites with extreme negative values on axis 1 come from the Low Countries, which are known for having distinct animal exploitation patterns during the early Neolithic, with much higher frequencies of terrestrial wild animals.

In order to explore in more detail the cause of inter-regional variation between the four geographic zones, we examined the extent of intra-regional homogeneity in animal

(C) Antiquity Publications Ltd. 
C \& SW Mediterranean $(\mathrm{n}=97413)$

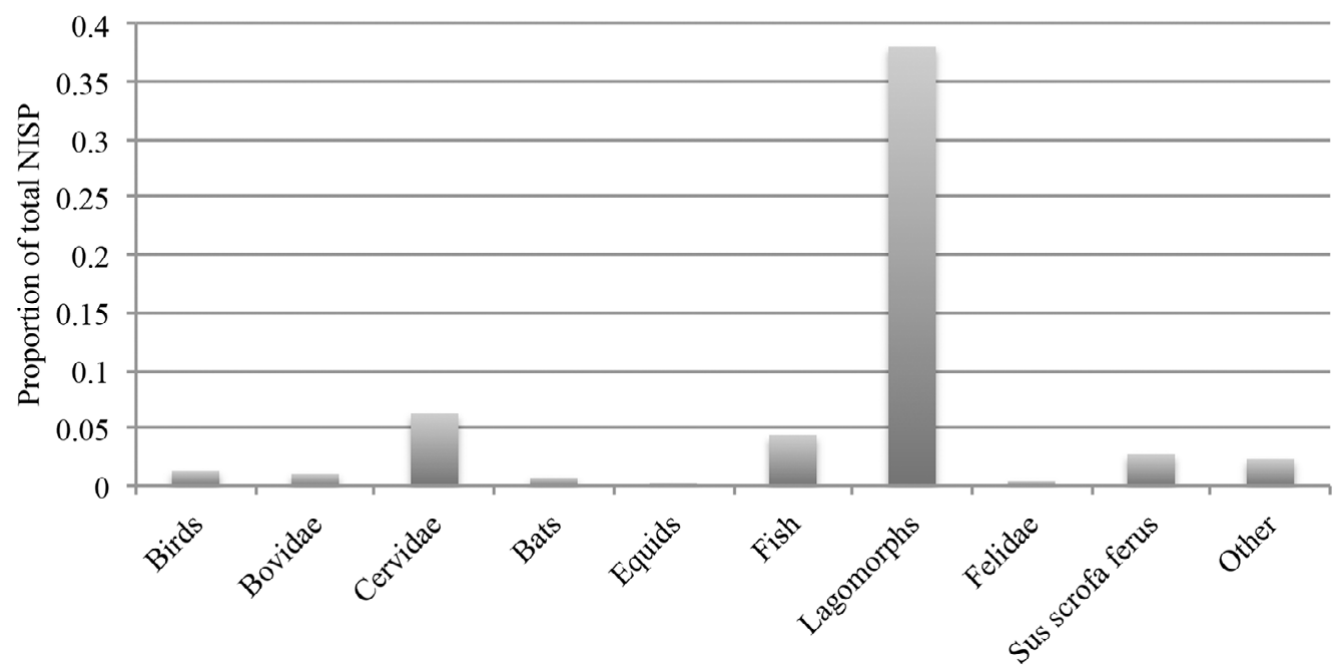

Figure 3. Proportional NISP counts of wild animals from site phases in the central and south-west Mediterranean.

exploitation patterns using the expanded taxa list. As shown in Figure 2 there is a greater representation of wild taxa at central and south-west Mediterranean sites (55 per cent of the total NISP, as opposed to a maximum of 19 per cent for any other region). We therefore grouped all non-domestic species to family or genus level, resulting in the 10 categories seen in Figure 3. It is clear from this figure that lagomorphs (rabbits, hares) predominate, contributing over 35 per cent of all non-domestic taxa across the region.

We then sub-divided the central and south-west Mediterranean assemblage into three groups; Spain/Portugal, Italy and south-eastern France (Table 3), in order to test the prevalence of lagomorphs at a trans-regional level. This revealed clear sub-regional patterns, with the majority of lagomorph remains coming from the south-eastern French sites. In contrast, and contrary to the trans-regional trend, domesticates predominate in Italy, Spain and Portugal. Hence the terrestrial wild signature for the central and south-west Mediterranean is less of a trans-regional pattern, and instead appears to be driven primarily by the exploitation of lagomorphs in south-eastern France.

It is worth taking into account regional patterns in settlement type when considering variation in animal exploitation patterns. Erosion events associated with the $6200 \mathrm{BC}$ climatic event have been indicated as a causal factor in the absence of open-air sites in the central and south-west Mediterranean (Berger 2005). Despite recent efforts to identify such settlements (see e.g. Binder et al. 2002; Perrin 2008), the majority of sites from this region (with published zooarchaeological assemblages) are still caves or rockshelters, often representing marginal activities, e.g. hunting or mobile herding. We therefore identified sites by region and country and then further classified them according to settlement type. The regional groups reveal considerable discrepancies, supporting the prevalence of zooarchaeological assemblages from cave/rockshelter sites in the central and south-west Mediterranean and nowhere else (Table 4). However, when the region was sub-divided into (C) Antiquity Publications Ltd. 
Table 3. Relative proportions (\%) of NISP counts from Spain/Portugal, Italy and south-eastern France.

\begin{tabular}{lccc}
\hline & South-eastern France & Italy & Spain/Portugal \\
\hline Domesticates & 30.5 & 60.8 & 59.3 \\
Birds & 1.3 & 1.3 & 1.2 \\
Bovidae & 0.5 & 4.1 & 0.3 \\
Cervidae & 4.3 & 9.1 & 9.2 \\
Bats & 1.2 & 0.0 & 0.0 \\
Equidae & 0.0 & 0.1 & 0.1 \\
Fish & 2.9 & 16.0 & 0.4 \\
Lagomorphs & 54.5 & 2.3 & 23.2 \\
Felidae & 0.3 & 1.1 & 0.2 \\
Sus scrofa ferus & 2.3 & 2.2 & 4.1 \\
Other & 2.3 & 2.8 & 2.0 \\
TOTAL & $\mathbf{5 6 9 0 3}$ & $\mathbf{1 5 7 2 8}$ & $\mathbf{2 4 7 8 2}$ \\
\hline
\end{tabular}

Table 4. Distribution of settlement types across the four key regions of Europe.

\begin{tabular}{lcccc}
\hline & $\begin{array}{c}\text { South-east } \\
\text { Europe }\end{array}$ & $\begin{array}{c}\text { Central and south-west } \\
\text { Mediterranean }\end{array}$ & $\begin{array}{c}\text { Central } \\
\text { Europe }\end{array}$ & $\begin{array}{c}\text { North-west } \\
\text { Europe }\end{array}$ \\
\hline Settlement & 45 & 20 & 92 & 43 \\
Enclosure & 0 & 0 & 1 & 7 \\
Barrow/cemetery & 0 & 0 & 0 & 2 \\
Cave/rockshelter & 0 & 48 & 1 & 0 \\
Other & 0 & 1 & 0 & 3 \\
Total no. of sites & $\mathbf{4 5}$ & $\mathbf{6 9}$ & $\mathbf{9 4}$ & $\mathbf{5 5}$ \\
\hline
\end{tabular}

Table 5. Distribution of settlement types across the central and south-west Mediterranean.

\begin{tabular}{lccc}
\hline & South-eastern France & Italy & Spain/Portugal \\
\hline Cave/rockshelter & 24 & 9 & 15 \\
Settlement & 8 & 8 & 3 \\
Other & 0 & 0 & 1 \\
Total no. of sites & $\mathbf{3 2}$ & $\mathbf{1 7}$ & $\mathbf{1 9}$ \\
\hline
\end{tabular}

its three constituent countries, it becomes apparent that the prevalence of cave/rockshelter sites is trans-regional and does not correspond with the higher percentage of lagomorphs seen in the site phases from south-eastern France (Table 5). Cave/rockshelter localities do not, therefore, appear to be the cause of the variance seen between taxa. Furthermore, there was no obvious disparity in the recovery techniques between these regions. A simple linear regression between lagomorph NISP counts and cultural categories (cardial, epicardial and impressa) from the central and south-west Mediterranean also revealed little correlation $\left(0.07\right.$ adjusted $\left.\mathrm{R}^{2}\right)$ and the result was not significant at $<0.05$.

(C) Antiquity Publications Ltd. 
Table 6. Relative proportions (\%) of the key taxonomic groups from early Neolithic sub-regions and main cultural affiliations within central Europe.

\begin{tabular}{llcccrc}
\hline Culture & Country & Bos taurus & Ovis/Capra & Sus scrofa domesticus & Wild & Total NISP \\
\hline TRB & Germany & 19.90 & 6.09 & 5.69 & 67.02 & 9776 \\
LBK & Austria & 37.03 & 29.97 & 17.92 & 14.93 & 2009 \\
& Czech Republic & 63.30 & 17.24 & 11.21 & 7.67 & 2256 \\
& Germany & 40.50 & 19.37 & 21.15 & 18.81 & 32258 \\
& Hungary & 55.35 & 17.87 & 13.45 & 12.45 & 1606 \\
& Poland & 76.46 & 14.45 & 3.54 & 5.16 & 6547 \\
& Slovakia & 56.91 & 25.40 & 14.78 & 2.07 & 3098 \\
Rubané & France & 44.45 & 24.03 & 23.25 & 7.91 & 9598 \\
SBK & Czech Republic & 58.25 & 16.40 & 16.01 & 7.96 & 1018 \\
MK & Belgium & 53.17 & 9.69 & 14.53 & 21.80 & 867 \\
\hline
\end{tabular}

The other pattern to have emerged from the CA was congruence in the distribution of taxa in central and north and north-west Europe (Figure 2). In order to examine the geographical influence on these patterns, site phases with the main cultural affiliations for both regions were compared. In central Europe, the relative proportions of domestic taxa are strikingly similar from Poland to the Paris Basin (Table 6). This is perhaps not surprising as all but 9 of the 111 site phases from central Europe belong to the LBK or Rubané cultures. Some subtle differences can be seen, in particular in the relative proportions of the different livestock species, and these have been discussed in more detail elsewhere (e.g. Döhle 1993; Tresset \& Vigne 2001; Manning et al. 2013). The overall pattern for early Neolithic animal exploitation in central Europe, however, appears to have been highly standardised. Cattle predominate across the region, with sheep/goat and pigs contributing the secondary domestic resource. The TRB assemblages from northern Germany break from this trend, with a considerably greater proportion of terrestrial wild animals. Table 7 highlights the clear correspondence in the predominance of domestic taxa, particularly cattle, in the north and north-west European site phases and in central Europe. The fifth millennium BC Swifterbant phases from the Netherlands are considerably different, with an overwhelming majority of wild taxa (94 per cent), although this is not surprising in light of the fact that they almost certainly represent the uptake of cereals by local forager populations that continued hunting (Cappers \& Raemaekers 2008).

Other than the TRB and Swifterbant groups, therefore, the predominance of cattle appears to be consistent across most of central and north and north-west Europe, accounting largely for the patterns seen in Figure 2. These trends, however, contrast starkly with the animal exploitation patterns of the central and south-west Mediterranean. Even within central and north and north-west Europe, there are important differences in the relative proportions of different taxa, for example as seen in the high proportions of sheep/goat in Orkney, and in the predominance of lagomorphs in south-eastern France. But to what extent are these differences the product of ecological or cultural factors, or a combination of both? In the remainder of this paper we attempt to shed some light on this question.

(C) Antiquity Publications Ltd. 
Table 7. Relative proportions (\%) of the key taxonomic groups from early Neolithic sub-regions and main cultural affiliations within north and north-west Europe.

\begin{tabular}{llcccrr}
\hline Culture & Country & Bos taurus & Ovis/Capra & Sus scrofa domesticus & Wild & Total NISP \\
\hline Swifterbant & Netherlands & 1.27 & 0.93 & 0.25 & 94.24 & 1181 \\
VSG & France & 56.38 & 17.76 & 21.08 & 4.64 & 13718 \\
Rubané & France & 52.68 & 21.03 & 12.92 & 13.28 & 29649 \\
Cerny & France & 72.60 & 6.50 & 13.24 & 7.17 & 1646 \\
Chassey & France & 65.90 & 9.82 & 16.57 & 6.07 & 4642 \\
Southern Britain & England & 33.01 & 24.98 & 31.24 & 6.06 & 5592 \\
Orkney & Scotland & 46.80 & 52.38 & 0.57 & 0.21 & 4735 \\
\hline
\end{tabular}

Table 8. Multi-linear regression and ANCOVA results.

\begin{tabular}{|c|c|c|c|c|c|c|c|c|}
\hline & & \multicolumn{3}{|c|}{ Domestic } & \multicolumn{4}{|c|}{ Wild } \\
\hline & & $\begin{array}{c}\text { Bos } \\
\text { taurus }\end{array}$ & $\begin{array}{l}\text { Ovis/ } \\
\text { Capra }\end{array}$ & $\begin{array}{l}\text { Sus scrofa } \\
\text { domesticus }\end{array}$ & $\begin{array}{l}\text { Capreolus } \\
\text { capreolus }\end{array}$ & $\begin{array}{c}\text { Bos } \\
\text { primigenius }\end{array}$ & $\begin{array}{l}\text { Cervus } \\
\text { elaphus }\end{array}$ & $\begin{array}{l}\text { Sus scrofa } \\
\text { ferus }\end{array}$ \\
\hline \multirow{2}{*}{$\begin{array}{l}\text { Multi-linear } \\
\text { regression }\end{array}$} & $D F$ & 8 & 8 & 8 & 8 & 8 & 8 & 8 \\
\hline & Adjusted R2 & 0.28 & 0.30 & 0.23 & 0.08 & 0.11 & 0.04 & 0.01 \\
\hline Environment & $p$ & 0.00 & 0.00 & 0.00 & 0.00 & 0.00 & 0.02 & 0.33 \\
\hline ANCOVA & $D F$ & 20 & 20 & 20 & 20 & 20 & 20 & 20 \\
\hline \multirow{2}{*}{$\begin{array}{l}\text { Environment } \\
+ \text { culture }\end{array}$} & Adjusted R2 & 0.40 & 0.35 & 0.40 & 0.21 & 0.14 & 0.19 & 0.06 \\
\hline & $p$ & 0.00 & 0.00 & 0.00 & 0.00 & 0.00 & 0.00 & 0.04 \\
\hline
\end{tabular}

\section{Results of the spatial analysis}

We constructed a correlation matrix (not shown) of the 11 environmental variables listed in Table 2 and eliminated three that were highly inter-correlated (tpmin, tprng and tpmax $\mathrm{R}^{2}$ $>0.75$ ). Subsequent results of the multi-linear regression (Table 8) suggest that environment alone accounts for a considerable proportion of the variance observed in the domestic taxa. This is in accordance with recent results on the goodness of fit between environmental data and early Neolithic cattle abundance in the Near East and south-east Europe (Conolly et al. 2012), where a multi-linear regression analysis revealed that up to of 20 per cent of the variance in cattle frequencies was accounted for by environmental variables. Our results substantiate this claim, although our $\mathrm{R}^{2}$ values are in fact higher, with 28 per cent of the variability in cattle being accounted for by environment, 30 per cent for sheep/goat and 23 per cent for pigs. This improvement in the environmental model is likely due to the larger geographic area covered in our study, and hence the greater relative variation in environmental variables, as compared to those in the study by Conolly and colleagues. In contrast to the domesticates, the wild taxa produced considerably lower adjusted $\mathrm{R}^{2}$ values, with environment accounting for only $8-11$ per cent of the variance in roe deer and aurochs, and only 4 per cent in red deer. The regressions are statistically significant at $<0.05$ for all of these taxa. The results for wild boar, were, in contrast, not significant at $<0.05$ for the multi-linear regression as well as the partial ANOVAs.

(C) Antiquity Publications Ltd. 
Table 9. ANOVA partial correlation results.

\begin{tabular}{ccccccccccc}
\hline & & \multicolumn{3}{c}{ Domestic } & & \multicolumn{3}{c}{ Wild } \\
\cline { 3 - 5 } \cline { 8 - 10 } & & $\begin{array}{c}\text { Bos } \\
\text { taurus }\end{array}$ & $\begin{array}{c}\text { Ovis/ } \\
\text { Capra }\end{array}$ & $\begin{array}{c}\text { Sus scrofa } \\
\text { domesticus }\end{array}$ & $\begin{array}{c}\text { Capreolus } \\
\text { capreolus }\end{array}$ & $\begin{array}{c}\text { Bos } \\
\text { primigenius }\end{array}$ & $\begin{array}{c}\text { Cervus } \\
\text { elaphus }\end{array}$ & $\begin{array}{c}\text { Sus scrofa } \\
\text { ferus }\end{array}$ \\
\hline Partial & $D F$ & 12 & 12 & 12 & & 12 & 12 & 12 & 12 \\
ANOVA & Adjusted R2 & 0.10 & 0.00 & 0.13 & & 0.13 & 0.01 & 0.13 & 0.01 \\
Culture & $p$ & 0.00 & 0.37 & 0.00 & & 0.00 & 0.24 & 0.00 & 0.24 \\
\hline
\end{tabular}

Incorporating culture as an independent factor in an additive ANCOVA model provides additional explanatory power in accounting for the NISP frequency distributions (Table 8). The distribution of domestic taxa and the two species of deer appear to be most strongly affected, showing an increase of up to 17 per cent in the adjusted $\mathrm{R}^{2}$ value.

Results of the partial correlation on culture with environment kept constant (Table 9) help to explain the additional explanatory power of the ANCOVA. Around 10-13 per cent of the variation in NISP frequencies for cattle, pig, roe deer and red deer can be accounted for by cultural affiliation. For these four species, the result is statistically significant at $<0.05$. For the three remaining species, the results are not significant at $>0.05$.

\section{Discussion}

We set out to characterise and quantify broad-scale patterns in the distribution of animal bone data from the early and middle Neolithic in Europe, and to test the relative influence of cultural $v$ s ecological factors on the regionalisation of hunting/herding strategies. Whilst the animal bone assemblages from central and north and north-west Europe demonstrate a high degree of similarity, particularly in the predominance of domestic cattle, followed either by sheep/goat or pig, those of the central and south-west Mediterranean are clearly distinct with a greater representation of sheep/goat and terrestrial wild taxa. These patterns support existing hypotheses for two routes of dispersal — continental and Mediterraneanof animal domesticates (e.g. Cymbron et al. 2005; Tresset \& Vigne 2007; Coward et al. 2008; Vigne 2008), although results of the multi-linear regression suggest these two routes may, to a large extent, be reflecting the selective effects of environment on early Neolithic herding strategies.

Despite these broad-scale distinctions, however, there is clear variation within regions. In the central and south-west Mediterranean, wild taxa, particularly lagomorphs, dominate at the regional level. Nonetheless, a more detailed examination of the distribution of specific taxa reveals a high degree of local variation, with the relative importance of wild animals being significantly inflated by an abundance of lagomorphs in south-eastern France. As this does not appear to be a consequence of settlement type, nor of cultural affiliation, it raises the question of why lagomorphs were so intensively exploited in south-eastern France?

Elsewhere we have demonstrated a marked shift in exploitation strategies during the early LBK, particularly in southern Germany (Manning et al. 2013), and it is evident that similar processes of local development would have characterised much of the European Neolithic.

(C) Antiquity Publications Ltd. 
That said, the results presented here suggest that a large proportion of the temporal and cultural variation becomes masked (see below) when we deal with continental-scale datasets.

Results of the geo-spatial analysis show that environment has the greatest influence on animal exploitation during the early Neolithic. Domestic taxa demonstrate the best correlation (23-30 per cent of the variance accounted for), in contrast to the wild taxa, which show considerably less at 1-11 per cent. This is clearly a counter-intuitive result: species distribution amongst wild taxa is governed by availability of resources and ecological limits of adaptation. The distribution of domesticates, meanwhile, should be less environmentally constrained as a result of human intervention by, for example, watering and supplementing winter fodder. We would therefore expect a stronger correlation between wild taxa and environment, and a lower correlation with domestic taxa. However, our contrary results can be explained by the fact that what we are measuring is a correlation between wild taxa and environments at locations that are almost certainly not selected to maximise encounter rates of wild game. In other words, they are not in the best hunting locations, but are instead selected for a myriad reasons that include suitability for agriculture and herding and other resource needs (wood, flint, clay, etc.) as well as wild game availability. This may explain why the domestic/environment correlation is high, and the wild/environment correlation is low. We predict that if we tested Mesolithic sites from the same study area the correlation would be higher because remains of wild animals are more likely to be deposited in the same ecozone in which they were hunted.

Despite finding a good correlation between the domestic taxa and environment, a large portion of the variance remains unexplained. Nonetheless, it is worth taking into account the complexity of the data we are dealing with. Zooarchaeological data are subject not only to depositional and recovery biases, but also to a lack of standardisation in recording techniques. The fact that we are able to observe any patterning in our data, and at such a broad continental scale, makes these results even more remarkable. Furthermore we are using modern (averaged records from 1950 to 2000) rather than reconstructed environmental data in this analysis. With greater resolution of the palaeoenvironmental conditions of Neolithic Europe, it is likely that these results could be improved.

The additive ANCOVA model adds important explanatory power, with environment and culture explaining up to 40 per cent of the observed variation in NISP counts. The partial correlation shows that culture-that is to say, differences in the cultural affiliation of the sites-provides an additional 12-13 per cent of explanatory power, although only in the case of cattle, pig, roe deer and red deer.

This research confirms the presence of clear regional patterns in the animal exploitation strategies of early Neolithic farmers in Europe. More importantly (and for the first time) we demonstrate the explanatory power of environment as a predictive factor for taxonomic variation in the composition of animal bone assemblages, more so than cultural affiliation. Our analysis also reveals higher adjusted $\mathrm{R}^{2}$ values for domestic taxa when compared to their wild counterparts, reflecting the selective effects of environment on early Neolithic herding strategies. In this analysis we have focused on taxonomic variation, and whilst we have been unable to identify a strong correlation between species and cultural affiliation, this does not negate culture as a predictor of animal exploitation strategies. The use of secondary resources, mobility patterns or breed diversity may, for example, be more affected by cultural

(C) Antiquity Publications Ltd. 
variation. For this we need to examine other types of evidence, such as demographic (age/sex profiles) and phenotypic (biometry and ancient DNA) variation. It is also apparent that a considerable degree of temporal and cultural detail is lost when dealing with such a large dataset. We are now in the process of collecting data from all Neolithic phases from northwest Europe as part of a new European research initiative (EUROEVOL n.d.). The next stage of this analysis is therefore to use this data to investigate other aspects of Neolithic herding behaviour, and to examine how these continental-scale patterns relate to local scale practice.

\section{Acknowledgements}

We thank the Arts and Humanities Research Council (AHRC) for funding the Origin and Spread of Stockkeeping (OSSK) project and the European Research Council for its grant to the project 'EUROEVOL: Cultural Evolution of Neolithic Europe' for making possible the continued analysis of the OSSK data in the framework of the new project. We are grateful to Pascale Gerbault and Adrian Timpson for their comments on the statistical methods and to Elisabeth Llado for her work on the Spanish data.

\section{References}

Arbogast, R.-M., C. Jeunesse \& J. Schibler (ed.). 2001. Rôle et Statut de la Chasse dans le Néolithique ancien danubien (5500-4900 av. J.-C.)

(Internationale Archäologie 1). Rahden: Marie Leidorf.

BERGER, J.-F. 2005. Sédiments, dynamique du peuplement et climat au Néolithique ancien, in J. Guilaine (ed.) Populations néolithiques et environnements: 155-212. Paris: Errance.

Binder, D., L. Jallot \& S. Thiébault. 2002. Fiche 9: les occupations néolithiques des Petites-Bâties (Lamotte-du-Rhône, Vaucluse), in Association pour la Recherche Archéologique en Languedoc Oriental (ed.) Archéologie du TGV Méditerranée. Fiches de synthèse. Tome 1. La Préhistoire (Monographies d'Archéologie Mediterranéenne 8): 103-22. Lattes: CNRS.

BOCQUET-APPEL, J.-P. \& O. BAR-YoseF (ed.). 2008. The Neolithic demographic transition and its consequences. New York: Springer.

Bonsall, C., M. Macklin, D.E. ANderson \& R.W. PAYTON. 2002. Climate change and the adoption of agriculture in northwest Europe. European Journal of Archaeology 5: 9-23.

Cappers, R.T.J. \& D.C.M. Raemaekers. 2008. Cereal cultivation at Swifterbant? Neolithic wetland farming on the North European plain. Current Anthropology 49: 385-402.

Collard, M., K. Edinborough, S. Shennan \& M.G. ThOMAs. 2010. Radiocarbon evidence indicates that migrants introduced farming to Britain. Journal of Archaeological Science 37: 866-70.

Colledge, S., J. Conolly \& S. Shennan. 2005. The evolution of Neolithic farming from SW Asian origins to NW European limits. European Journal of Archaeology 8: 137-56.

(C) Antiquity Publications Ltd.
Conolly, J., S. Colledge, K. Dobney, J.-D. Vigne, J. Peters, B. Stopp, K. Manning \& S. Shennan. 2011. Meta-analysis of zooarchaeological data from SW Asia and SE Europe provides insight into the origins and spread of animal husbandry. Journal of Archaeological Science 38: 538-45.

Conolly, J., K. Manning, S. Colledge, K. Dobney \& S. SHENNAN. 2012. Species distribution modelling of ancient cattle from early Neolithic sites in SW Asia and Europe. The Holocene 22: 997-1010.

Coward, F., S. Shennan, S. Colledge, J. Conolly \& M. COllard. 2008. The spread of Neolithic plant economies from the Near East to northwest Europe: a phylogenetic analysis. Journal of Archaeological Science 35: 42-56.

CRAWLEY, M.J. 2005. Statistics: an introduction using $R$. Chichester: Wiley.

Cymbron, T., A.R. Freeman, M.I. Malheiro, J.-D. Vigne \& D.G. BRADLEY. 2005. Microsatellite diversity suggests different histories for Mediterranean and northern European cattle populations. Proceedings of the Royal Society B 272: $1837-43$.

DE JAGER, A.L. \& J.V. VogT. 2010. Development and demonstration of a structured hydrological feature coding system for Europe. Hydrological Sciences Journal 55: 661-75.

DöHLE, H.-J. 1993. Haustierhaltung und Jagd in der Linienbandkeramik: ein Überblick. Zeitschrift für Archäologie 27: 105-24.

- 1997. Husbandry and hunting in the Neolithic of central Germany. Anthropozoologica 25/26: 441-48.

ESRI Environmental Systems Resource Institute. 2009. ArcMap 9.2. Redlands (CA): ESRI. 
EUROEVOL. n.d. The cultural evolution of Neolithic Europe. Available at: http://www.ucl.ac.uk/ euroevol/EUROEVOL/Home.html (accessed 17 December 2012).

Harman, M. 2009. The animal bones, in A. Ritchie (ed.) On the fringe of Neolithic Europe: 48-59. Edinburgh: Society of Antiquaries of Scotland.

Hijmans, R.J., S.E. Cameron, J.L. Parra, P.G. Jones \& A. JARVIS. 2005. Very high resolution interpolated climate surfaces for global land areas. International Journal of Climatology 25: 1965-78.

LEgENDRE, P. \& L. LEGENDRE. 1998. Numerical ecology. Amsterdam: Elsevier.

Manning, K., B. Stopp, S. Colledge, S. Downey, J. Conolly, K. Dobney \& S. Shennan. 2013. Animal exploitation in the early Neolithic of the Balkans and central Europe, in S. Colledge, J. Conolly, K. Dobney, K. Manning \& S. Shennan (ed.) The origins and spread of domestic animals in southwest Asia and Europe: 237-52. Walnut Creek (CA): Left Coast.

McCormick, F. 1984. Large mammal bone, in N. Sharples (ed.) Excavations at Pierowall Quarry, Westray, Orkney. Proceedings of the Society of Antiquaries of Scotland 114: 108-11.

PERrin, T. 2008. La néolithisation de la vallée du Rhône et de ses marges, in S. Grimaldi \& T. Perrin (ed.) Mountain environments in prehistoric Europe: settlement and mobility strategies from the Palaeolithic to the Early Bronze Age (British Archaeological Reports international series 1885): 121-30. Oxford: Archaeopress.

R Development Core Team. 2011. R: a language and environment for statistical computing. Vienna: $\mathrm{R}$ Foundation for Statistical Computing. Available at: http://www.R-project.org/ (accessed 3 July 2012).
Rowley-Conwy, P., L. Gourichon, D. Helmer \& J.-D. VIGNE. 2013. Early domestic animals in Italy, Istria, the Tyrrhenian Islands, and southern France, in S. Colledge, J. Conolly, K. Dobney, K. Manning $\&$ S. Shennan (ed.) The origins and spread of domestic animals in southwest Asia and Europe: 283-311. Walnut Creek (CA): Left Coast.

SCHibler, J. \& S. JACOMET. 2010. Short climatic fluctuations and their impact on human economies and societies: the potential of Neolithic lake shore settlements in the Alpine foreland. Environmental Archaeology 15(2): 61-70.

SCHulting, R. 2013. On the northwestern fringes: earlier Neolithic subsistence in Britain and Ireland as seen through faunal remains and stable isotopes, in S. Colledge, J. Conolly, K. Dobney, K. Manning \& S. Shennan (ed.) The origins and spread of domestic animals in southwest Asia and Europe: 313-38. Walnut Creek (CA): Left Coast.

Tresset, A. \& J.-D. Vigne. 2001. La Chasse, principal élément structurant la diversité des faunes archéologiques du Néolithique ancien, en Europe tempérée comme en Méditerranée, in R.-M. Arbogast, C. Jeunesse \& J. Schibler (ed.) Rôle et Statut de la Chasse dans le Néolithique ancien danubien (5500-4900 av. J.-C.) (Internationale Archäologie 1): 129-51. Rahden: Marie Leidorf.

-2007 . Substitution of species, techniques and symbols at the Mesolithic-Neolithic transition in western Europe. Proceedings of the British Academy 144: 189-210.

Vigne, J.-D. 2008. Zooarchaeological aspects of the Neolithic diet transition in the Near East and Europe, and their putative relationships with the Neolithic demographic transition, in J.-P. Bocquet-Appel \& O. Bar-Yosef (ed.) The Neolithic demographic transition and its consequences: 179-205. New York: Springer.

Received: 15 October 2012; Accepted: 15 December 2012; Revised: 17 December 2012

(C) Antiquity Publications Ltd. 